\title{
Formas de Transmissão do HIV: Conhecimento de Acadêmicos de Fisioterapia e Fatores Associados
}

\author{
Luana Bianchini ${ }^{1}$, Ramison Santos ${ }^{2}$, Renata D'Agostini Nicolini-Panisson ${ }^{3}$, \\ Maria Luisa Gregolleto ${ }^{4}$, Cleber Cremonese ${ }^{5}$
}

\begin{abstract}
RESUMO
A investigação avaliou o nível de conhecimento insatisfatório quanto às formas de transmissão do vírus HIV e possíveis fatores associados em acadêmicos de um curso de Fisioterapia. Foram utilizados questionários autoaplicáveis, compostos de 32 questões, divididas em sociodemográficas, educacionais, de acesso à informação e relativas às possíveis formas de transmissão do vírus HIV. Participaram do estudo 296 acadêmicos, com predomínio do sexo feminino $(86,5 \%)$ e com idade $\leq 21$ anos $(54,7 \%)$. Encontrou-se maior frequência de brancos, solteiros e com renda $\leq 5$ salários mínimos. Quanto à educação e acesso, a maior parte estudou em escola pública $(73,3 \%)$, possuía acesso à Internet $(96,6 \%)$ e leram $\leq 2$ livros no último ano $(53,4 \%)$. Conhecimento insatisfatório sobre as formas de transmissão do HIV esteve associado aos mais jovens, solteiros, com $<50 \%$ das disciplinas do curso concluídas e sem hábito regular de leitura. Por fim, na análise ajustada, apresentar idade $\leq 21$ anos $(R P=1,97)$ e ter lido $\leq 2$ livros no último ano $(R P=1,40)$ mantiveram associação significativa $(p<0,05)$ com o desfecho. Diante deste cenário, palestras e incentivo à leitura surgem como algumas das propostas para melhorar o conhecimento técnico dos acadêmicos de Fisioterapia, demais estudantes ou profissionais da área da saúde.
\end{abstract}

Palavras-chave: Infecções por HIV. Conhecimento. Fisioterapia. Estudos transversais. Epidemiologia.

FORMS OF HIV TRANSMISSION: KNOWLEDGE OF PHYSIOTHERAPY ACADEMICS AND ASSOCIATED FACTORS

ABSTRACT

The research assessed the Physical Therapy major students' unsatisfactory knowledge of the ways the HIV virus is transmitted and possible related factors. Self-administered 32-question forms were used with topics ranging from social-demographics, access to information, educational value to the possible ways of HIV transmission. The study included 296 students; mostly female respondents ( $86.5 \%)$, aged $\leq 21$ years $(54.7 \%)$. Also higher frequency were single, white, whose income is $\leq 5$ minimum wages. As for education and access, most respondents went to public schools $(73.3 \%)$, had access to the Internet $96.6 \%$ and students that had read $\leq 2$ books in the previous year represented $53.4 \%$. Little knowledge of HIV transmission was associated with younger, single, with $<50 \%$ of their college disciplines finished and without regular reading habits. Lastly, in the adjusted analysis, those of age $\leq 21$ years $(P R=1.97)$ and those who read $\leq 2$ books last year ( $P R=1.40)$ remained significantly consistent $(p<0.05)$ with the outcome. In this scenario, lectures and encouraging reading emerge as some of the proposals to improve the technical knowledge of physical therapy students, healthcare workers and other students in general.

Keywords: HIV Infections. Knowledge. Physical therapy specialty. Cross-sectional studies. Epidemiology.

Recebido em: $11 / 3 / 2017$

Aceito em: 27/2/2018

\footnotetext{
Acadêmica do curso de Fisioterapia - Centro Universitário da Serra Gaúcha. lubianchinii@yahoo.com.br

Acadêmico do curso de Biomedicina - Centro Universitário da Serra Gaúcha. Orcid: <http://orcid.org/0000-0003-2679-2512>. ramisonsantos@yahoo.com.br

3 Docente no Centro Universitário da Serra Gaúcha. renata.panison@fsg.br

${ }_{4}^{4}$ CDocente no Centro Universitário da Serra Gaúcha. maria.gregoletto@fsg.br

5 Docente no Centro Universitário da Serra Gaúcha. Orcid: <http://orcid.org/0000-0003-2700-7416>. cleber.cremonese@fsg.br
} 


\section{INTRODUÇÃO}

A Síndrome da Imunodeficiência Adquirida (Aids), causada pelo vírus HIV, é a quinta maior causa mundial de morte, entre os adultos jovens (WORLD..., 2015). Dados recentes mostram que 35 milhões de pessoas encontram-se infectadas pelo HIV no planeta (AGARWAL et al., 2015), dos quais 718 mil casos encontram-se no Brasil (MAGALHÃES; OLIVEIRA; PRADO, 2015), com uma taxa de incidência de 20,2/100 mil, mensurada no ano de 2012 (AFFELDT; SILVEIRA; BARCELOS, 2015). Ainda no cenário nacional, as taxas mais elevadas são encontradas na Região Sul, com prevalência entre 17\% a 19\% (MAGALHÃES; OLIVEIRA; PRADO, 2015).

Quanto ao contágio pelo vírus HIV, esta ameaça apresenta-se cada vez menos concentrada e, atualmente, os grupos de risco não estão mais restritos apenas entre os homossexuais, usuários de drogas e profissionais do sexo, mas sim na população em geral (ARIAS; LUJÁN-TANGARIFE, 2015). Ocupacionalmente, entre as classes com risco de contaminação, profissionais da saúde apresentam uma prevalência de 0,3\% de contágio (AGARWAL et al., 2015), em que $90 \%$ das contaminações ocorrem em trabalhadores de países em desenvolvimento, o que pode estar associado à negligência na segurança do trabalho e ao desconhecimento sobre as formas de contaminação (RYALAT et al., 2011). Acrescenta-se a isso o relato de dificuldades e medo em atender pacientes portadores do vírus HIV, podendo essa conduta resultar na recusa ao atendimento ou na tomada de atitudes equivocadas, colocando em risco pacientes e profissionais (VERMA et al., 2014).

Diante deste contexto, ações preventivas quanto às formas de contaminação e medidas de proteção são necessárias, tornando-se imprescindível a obtenção de conhecimento sobre a enfermidade e, principalmente, das suas vias de transmissão. Nesta perspectiva, acadêmicos da área da saúde, como futuros profissionais, devem se manter atualizados quanto a estes conhecimentos e receber capacitações, caso necessário. Dessa forma, os trabalhadores da saúde que recebem conhecimentos apropriados e atualizados sobre o HIV aumentam sua capacidade para melhor atender pacientes soropositivos, apresentando maior confiança e executando medidas adequadas para o autocuidado (RYALAT et al., 2011; SILVA et al., 2013).

Ainda em relação ao conhecimento sobre a enfermidade, estudos realizados para identificar a compreensão de acadêmicos e profissionais da área da saúde revelam um satisfatório entendimento geral quanto ao vírus e à transmissão, porém em situações laborais específicas identifica-se uma alta prevalência de incertezas e o relato, por parte dos estudantes da saúde, sobre não se sentirem preparados para trabalhar com essa população (MAGALHÃES; OLIVEIRA; PRADO, 2015; VASCONCELOS; COÊLHO, 2013; PUNDE; PUNDE, 2014).

Nesse sentido, ainda são poucos os estudos que avaliam os níveis de conhecimento dos profissionais e acadêmicos da área da saúde quanto ao HIV/ Aids, destacando-se que os existentes estão concentrados, principalmente, na área da Odontologia (PUNDE; PUNDE, 2014, MOURA et al., 2014; HAMERSHOCK, 2014) e Medicina (MARZÁN-RODRÍGUEZ; VARAS-DÍAZ, 2015; MEMISH et al., 2015). Enfermagem (FAROTIMI; NWOZICHI; OJEDIRAN, 2015), Farmácia (VASCONCELOS; COÊLHO, 2013), Psicologia (VASCONCELOS; FELIX, 2015) e Fisioterapia (SILVA et al., 2013) são áreas que também apresentam estudos publicados.

O objetivo do presente estudo, portanto, foi avaliar o nível de conhecimento insatisfatório quanto às formas de transmissão do vírus HIV e possíveis fatores associados, entre acadêmicos do curso de Fisioterapia de uma instituição privada no Sul do Brasil.

\section{MÉTODOS}

Trata-se de um estudo epidemiológico observacional com delineamento transversal, realizado em uma Instituição de Ensino Superior (IES), na cidade de Caxias do Sul/RS. Para isso, a amostra foi composta por 296 acadêmicos, regularmente matriculados no curso de Fisioterapia da Faculdade da Serra Gaúcha (FSG), os quais estivessem cursando, ao menos, uma disciplina da Graduação no período de coleta de dados, e que apresentassem condições físicas para responder ao questionário autoaplicável.

Para a coleta de dados foi utilizado um questionário autoaplicável, composto por 32 questões, construído pelos pesquisadores responsáveis pelo planejamento e execução do estudo. Para verificar a confiabilidade do método escolhido na execução do estudo e validação do instrumento foi realizada uma aplicação-piloto, com 10 estudantes, formandos em Fisioterapia no período de $2015 / 2$, na FSG. Os alunos que participaram do estudo-piloto não foram incluídos na pesquisa.

O instrumento apresentou questões sociodemográficas, de acesso à informação e características educacionais, além de variáveis com potencial para medir o nível de conhecimento sobre as formas de transmissão do vírus HIV, objetivo do estudo. 
Os aspectos sociodemográficos coletados no questionário foram: sexo (masculino e feminino), idade (coletada de forma contínua e categorizada em $\geq 22$ e $\leq 21$ ), raça/etnia (branca e negra/parda/outras), estado civil (casado/união estável/outros e solteiro), número de pessoas que moram na casa do acadêmico (coletada de forma contínua e categorizada em $\leq 3$ e $\geq 4$ ) e renda familiar (coletada em salários mínimos e categorizada em $\geq 6$ e $\leq 5$ ).

As questões comportamentais e ocupacionais foram investigadas por meio das variáveis: o tipo de escola em que frequentou o Ensino Médio (pública, particular/privada e pública e privada), disciplinas completadas no curso de Fisioterapia ( $\geq 50 \%$ e $<50 \%$ ), se possui acesso à Internet (sim e não), o objetivo do acesso à Internet (estudo/ buscar material de apoio didático e redes sociais/lazer), a quantidade de horas diárias de acesso à Internet (coletada de forma contínua e categorizada em $\geq 5$ e $\leq 4$ ), quantidade de livros não didáticos lidos no último ano (coletada de forma contínua e categorizada em $\geq 3$ e $\leq 2$ ), horas diárias em frente à televisão (coletada de forma contínua e categorizada em $\geq 3$ e $\leq 2$ ), programação de TV que costuma assistir (documentários/reportagens e filmes/seriados/novelas/esporte/lazer), se tem por costume falar sobre sexualidade com amigos/familiares ( $\operatorname{sim}$ e não) e a participação em cursos/palestras relacionados ao tema HIV/Aids (sim e não).

Para a coleta de informações relacionadas ao desfecho do estudo, "conhecimento insatisfatório sobre as formas de transmissão do vírus HIV", foram elaboradas 15 frases afirmativas, sendo elas: 1) O vírus HIV pode ser transmitido facilmente por meio do beijo; 2) O vírus HIV pode ser transmitido pelo abraço ou aperto de mão; 3 ) $O$ vírus HIV pode ser transmitido por meio do sexo oral sem preservativo; 4) O vírus HIV pode ser transmitido pelo compartilhamento de utensílios de cozinha (copo, talheres, etc.); 5) O vírus HIV pode ser transmitido mediante o compartilhamento de assentos sanitários; 6) $O$ vírus HIV pode ser transmitido por meio do sexo anal sem preservativo; 7) A relação sexual sem ejaculação pode ser uma forma de prevenir a transmissão do HIV; 8) O vírus HIV pode ser transmitido por microrganismos expelidos pela tosse, escarro e espirros; 9) O vírus HIV pode ser transmitido por meio de objetos terapêuticos compartilhados, como macas, bolas e halteres; 10) O vírus HIV pode ser transmitido pela transfusão de sangue; 11) O vírus HIV pode ser transmitido mediante o contato de feridas abertas do paciente com a pele íntegra do terapeuta; 12) O vírus HIV pode ser transmitido por meio da relação sexual vaginal sem preservativo; 13)
O vírus HIV pode ser transmitido por intermédio do compartilhamento de agulhas e seringas; 14$)$ O vírus HIV pode ser transmitido pela água, no compartilhamento de piscinas ou banheiras; 15) O vírus HIV pode ser transmitido por meio do contato de feridas abertas do paciente com a presença de feridas abertas do terapeuta.

Para essas afirmações os estudantes tinham as seguintes opções de resposta: concordo totalmente, concordo parcialmente, discordo parcialmente e discordo totalmente. Todas as 15 frases continham apenas uma possibilidade de resposta correta (Quadro 1), assim, cada acadêmico apresentou uma pontuação de acertos que variou entre zero (todas as respostas erradas) e 15 pontos (todas as respostas corretas).

A classificação do desfecho "conhecimento insatisfatório sobre as formas de transmissão do vírus HIV" foi realizada por meio do número de acertos para as 15 frases afirmativas, em que aqueles acadêmicos que apresentaram o número de acertos inferior a 11 (valor da mediana) foram classificados com conhecimento insatisfatório.

A aplicação dos questionários foi realizada nas três primeiras semanas do mês de março de 2016. Todas as turmas da IES que apresentassem acadêmicos do curso de Fisioterapia foram identificadas e, durante o período de aula, após a autorização do professor ministrante, para aqueles estudantes elegíveis, foi entregue o Termo de Consentimento Livre e Esclarecido (TCLE). Na sequência, após a devolução dos Termos, cada acadêmico recebeu um envelope pardo, contendo o questionário e, após o término do preenchimento, ocorreu a compilação das respostas simultaneamente. Destaca-se que não houve identificação do participante no instrumento de coleta de dados, de modo a garantir seu anonimato na investigação.

A construção do banco de dados e as análises estatísticas foram realizadas por meio do programa SPSS Statistic Data 20 (Statistical Package for Social Sciences - Chicago, IL, 2008). A análise descritiva das variáveis estudadas foi realizada por intermédio de valores absolutos, frequências e prevalências do desfecho. A análise bruta foi feita observando-se as razões de prevalência e respectivos intervalos de confiança em $95 \%$ por meio do teste de qui-quadrado para heterogeneidade. A análise multivariada ou ajustada foi efetuada por meio da regressão de Poisson, que apresenta como medida de efeito a razão de prevalência, seguindo modelo hierarquizado para controle de variáveis de confundimento. No primeiro nível foram incluídas as variáveis sociodemográficas e no segundo as variáveis educacionais e de acesso à informação. 
Quadro 1 - Afirmativas utilizadas para medir o desfecho "conhecimento insatisfatório quanto às formas de transmissão do vírus HIV" entre acadêmicos do curso de Fisioterapia, em uma instituição privada do sul do Brasil.

Caxias do Sul, 2016

\begin{tabular}{|c|c|}
\hline Frases afirmativas & Resposta correta \\
\hline O vírus HIV pode ser transmitido facilmente através do beijo. & Discordo totalmente \\
\hline O vírus HIV pode ser transmitido pelo abraço ou aperto de mão. & Discordo totalmente \\
\hline O vírus HIV pode ser transmitido através do sexo oral sem preservativo. & Concordo totalmente \\
\hline $\begin{array}{l}\text { O vírus HIV pode ser transmitido através do compartilhamento de utensílio de cozinha } \\
\text { (copo, talheres, etc.). }\end{array}$ & Discordo totalmente \\
\hline O vírus HIV pode ser transmitido através do compartilhamento de assentos sanitários. & Discordo totalmente \\
\hline O vírus HIV pode ser transmitido através do sexo anal sem preservativo. & Concordo totalmente \\
\hline $\begin{array}{l}\text { A relação sexual, sem ejaculação, pode ser uma forma de prevenir a transmissão do vírus } \\
\text { HIV. }\end{array}$ & Discordo totalmente \\
\hline $\begin{array}{l}\text { O vírus HIV pode ser transmitido através de microrganismos expelidos pela tosse, escarro } \\
\text { e espirros. }\end{array}$ & Discordo totalmente \\
\hline $\begin{array}{l}\text { O vírus HIV pode ser transmitido através de objetos terapêuticos compartilhados, como } \\
\text { macas, bolas e halteres. }\end{array}$ & Discordo totalmente \\
\hline O vírus HIV pode ser transmitido através da transfusão de sangue. & Concordo totalmente \\
\hline $\begin{array}{l}\text { O vírus HIV pode ser transmitido através do contato de feridas abertas do paciente com a } \\
\text { pele íntegra do terapeuta. }\end{array}$ & Discordo totalmente \\
\hline O vírus HIV pode ser transmitido através da relação sexual vaginal sem preservativo. & Concordo totalmente \\
\hline O vírus HIV pode ser transmitido através do compartilhamento de agulhas e seringas. & Concordo totalmente \\
\hline $\begin{array}{l}\text { O vírus HIV pode ser transmitido através da água, com compartilhamento de banheiras } \\
\text { ou piscinas. }\end{array}$ & Discordo totalmente \\
\hline $\begin{array}{l}\text { O vírus HIV pode ser transmitido através do contato de feridas abertas do paciente com a } \\
\text { presença de feridas abertas do terapeuta. }\end{array}$ & Concordo totalmente \\
\hline O vírus HIV pode ser transmitido através do compartilhamento de agulhas e seringas. & Discord \\
\hline
\end{tabular}

As variáveis que atingiram até $20 \%$ de significância $(p \leq 0,20)$ na análise bruta foram incluídas no modelo final, no qual foi considerado um nível de significância de $5 \%(p<0,05)$ para identificar associação entre o desfecho e as variáveis de exposição.

O projeto de pesquisa foi aprovado por um Comitê de Ética em Pesquisa de acordo com a Resolução no 466/12 do Conselho Nacional de Saúde, sob parecer $n$ o 1.324.388 e CAAE: 50663515.0.0000.5668. Todos os acadêmicos participantes do estudo leram e assinaram um Termo de Consentimento Livre e Esclarecido, o qual autorizou a participação e publicação dos resultados de forma anônima.

\section{RESULTADOS}

A amostra foi composta de 296 estudantes, correspondendo a $92 \%$ dos acadêmicos matriculados no curso de Fisioterapia da instituição de ensino, no período da investigação. Houve um predomínio do sexo feminino $(86,5 \%)$ e estudantes com idade $\leq 21$ anos, brancos e solteiros representaram a maior parte dos investigados constituindo, respectivamente, $54,7 \%$, $88,2 \%$ e $81,1 \%$ da amostra. Com relação à quantidade de moradores na casa do acadêmico, 56,1\% apresentaram três ou menos moradores e $74,3 \%$ apresentaram renda familiar menor ou igual a cinco salários mínimos (Tabela 1).

Em relação às características educacionais e de acesso à informação, 73,3\% frequentaram o Ensino Médio em escola pública e $55,3 \%$ haviam realizado, no momento da coleta de dados, menos de $50 \%$ da das disciplinas ofertadas na Graduação do curso de Fisioterapia. Acesso à Internet foi relatado por $96,6 \%$ dos acadêmicos e utilizá-la com o objetivo principal de lazer e frequentar redes sociais foi informado por $56,1 \%$ dos entrevistados. Quanto às horas diárias em frente à televisão, 73,2\% disseram gastar, no máximo, 2 horas assistindo TV. Em relação à programação, o objetivo principal foi o lazer (84,8\%). Destaca-se a baixa prevalência de estudantes que costumam ler livros não didáticos, ou seja, 53,4\% dos acadêmicos leram 
Tabela 1 - Distribuição das variáveis sociodemográficas, prevalência de conhecimento insatisfatório quanto às formas de transmissão do HIV, razões de prevalência e IC 95\%, entre acadêmicos do curso de Fisioterapia, em instituição privada do sul do Brasil. Caxias do Sul, 2016

\begin{tabular}{|c|c|c|c|c|}
\hline Variáveis de exposição & n (\%) & $\begin{array}{c}\text { Conhecimento insatis- } \\
\text { fatório (\%) }\end{array}$ & $\begin{array}{l}\text { RP bruta } \\
\text { (IC 95\%) }\end{array}$ & p-valor* \\
\hline Sexo & & & & 0,243 \\
\hline Masculino & $40(13,5)$ & 32,5 & 1 & \\
\hline Feminino & $256(86,5)$ & 43,0 & $1,32(0,83-2,11)$ & \\
\hline Idade (anos) & & & & $<0,001$ \\
\hline$\geq 22$ & $134(45,3)$ & 24,6 & 1 & \\
\hline$\leq 21$ & $162(54,7)$ & 55,6 & $2,26(1,61-3,13)$ & \\
\hline Etnia/ raça & & & & 0,845 \\
\hline Branca & $261(88,2)$ & 41,8 & 1 & \\
\hline Negra/Parda/Outra & $35(11,8)$ & 40,0 & $0,96(0,62-1,47)$ & \\
\hline Estado civil & & & & $<0,001$ \\
\hline Casado (a)/união estável/outros & $56(18,9)$ & 19,6 & 1 & \\
\hline Solteiro (a) & $240(81,1)$ & 46,7 & $2,38(1,37-4,11)$ & \\
\hline Moradores na casa do acadêmico & & & & 0,058 \\
\hline$\leq 3$ & $166(56,1)$ & 36,7 & 1 & \\
\hline$\geq 4$ & $130(43,9)$ & 47,7 & $1,30(0,99-1,70)$ & \\
\hline Renda familiar (em salários mínimos) & & & & 0,920 \\
\hline$\geq 6$ & $76(25,7)$ & 42,1 & 1 & \\
\hline$\leq 5$ & $220(74,3)$ & 41,4 & $0,98(0,71-1,35)$ & \\
\hline
\end{tabular}

RP - Razão de Prevalência.

* Teste qui-quadrado para heterogeneidade.

Valores em negrito são estatisticamente significativos $(p<0,05)$.

dois ou menos livros no último ano. Já a prevalência dos alunos que participaram, em algum momento da vida, de evento/palestra sobre o tema HIV/Aids, foi de $69,9 \%$, e que conversam sobre sexualidade com amigos e familiares foi de $64,9 \%$ (Tabela 2 ).

Quanto ao desfecho de interesse do presente estudo, o Gráfico 1 descreve resultados do conhecimento sobre as possíveis formas de transmissão do HIV, em que estão representadas as 15 afirmativas que foram utilizadas para medir esse conhecimento e suas frequências de respostas satisfatórias/corretas e insatisfatórias/incorretas. A prevalência geral do desfecho investigado foi de $41,6 \%$ (valor não apresentado em tabelas e gráficos). Quando medidos os conhecimentos sobre as possíveis formas de transmissão do HIV, as frequências elevadas de conhecimento insatisfatório foram: feridas abertas do paciente/pele íntegra do terapeuta $(67,9 \%)$, compartilhamento de assentos sanitários (49\%) e micro-organismos expelidos na tosse, escarro e espirros (48,6\%). Por outro lado, destaca-se a baixa prevalência de conhecimento insatisfatório em relação às variáveis que abordaram a transmissão por meio do sexo vaginal sem preservativo $(3,4 \%)$, por intermédio do compartilhamento de agulhas e seringas $(5,4 \%)$ e por transfusão de sangue $(5,7 \%)$.

Referente ao conhecimento insatisfatório das formas de transmissão do vírus HIV, as Tabelas $1 \mathrm{e}$ 2 trazem as prevalências do desfecho em relação às características sociodemográficas, educacionais e de acesso à informação. Destacam-se, como categorias com maiores prevalências insatisfatórias de conhecimento, a idade $\leq 21$ anos (55,6\%), o estado civil solteiro $(46,7 \%)$, residir em lares contendo $\geq 4$ habitantes $(47,7 \%)$, ter cursado $<50 \%$ das disciplinas ofertadas no curso $(50,9)$, acessar a Internet para frequentar redes sociais ou por lazer $(45,8 \%)$, ter lido $\leq 2$ livros no último ano $(46,2 \%)$ e assistir TV com objetivo de ver filmes/seriados/novelas/esporte/lazer (43,4\%).

Ainda nas Tabelas 1 e 2 são apresentadas as Razões de Prevalência (RP) brutas. Resultados considerados significativos, utilizados para montar o modelo ajustado $(p \leq 0,20)$, foram encontrados nas variáveis idade, estado civil, quantidade de moradores na casa do acadêmico, disciplinas completas no curso de Fisioterapia, objetivo principal de acesso à Internet, livros não didáticos lidos no último ano e qual programação 
Tabela 2 - Distribuição das variáveis educacionais e de acesso à informação, prevalência de conhecimento insatisfatório quanto às formas de transmissão do HIV, razões de prevalência e IC 95\%, entre acadêmicos do curso de Fisioterapia, em instituição privada do sul do Brasil. Caxias do Sul, 2016

\begin{tabular}{|c|c|c|c|c|}
\hline Variáveis de exposição & n (\%) & $\begin{array}{c}\text { Conhecimento } \\
\text { insatisfatório (\%) }\end{array}$ & RP bruta (IC 95\%) & p-valor* \\
\hline Formação no Ensino Médio & & & & 0,545 \\
\hline Pública & $217(73,3)$ & 40,6 & 1 & \\
\hline Particular/privada & $61(20,6)$ & 42,6 & $1,05(0,75-1,47)$ & \\
\hline Pública e privada & $17(5,7)$ & 52,9 & $1,31(0,81-2,10)$ & \\
\hline Disciplinas completas no curso de Fisioterapia & & & & $<0,001$ \\
\hline$\geq 50 \%$ & $132(44,7)$ & 29,5 & 1 & \\
\hline$<50 \%$ & $163(55,3)$ & 50,9 & $1,72(1,27-2,34)$ & \\
\hline Acesso à Internet & & & & 0,630 \\
\hline Sim & $286(96,6)$ & 42,0 & 1 & \\
\hline Não & $9(3,1)$ & 33,3 & $0,79(0,31-2,02)$ & \\
\hline Objetivo principal de acesso à Internet & & & & 0,101 \\
\hline Estudos/ buscar material didático & $130(43,9)$ & 36,2 & 1 & \\
\hline Redes sociais/Lazer & $166(56,1)$ & 45,8 & $1,27(0,95-1,68)$ & \\
\hline Horas diárias de acesso à Internet & & & & 0,969 \\
\hline$\geq 5$ & $157(54,3)$ & 44,6 & 1 & \\
\hline$\leq 4$ & $132(45,7)$ & 36,4 & $0,99(0,88-1,14)$ & \\
\hline Livros não didáticos lidos no último ano & & & & 0,047 \\
\hline$\geq 3$ & $138(46,6)$ & 36,2 & 1 & \\
\hline$\leq 2$ & $158(53,4)$ & 46,2 & $1,28(1,07-1,68)$ & \\
\hline Horas diárias assistindo TV & & & & 0,813 \\
\hline$\geq 3$ & $75(26,8)$ & 41,3 & 1 & \\
\hline$\leq 2$ & $205(73,2)$ & 42,9 & $1,04(0,76-1,42)$ & \\
\hline Qual programação costuma assistir na TV & & & & 0,153 \\
\hline Documentários/reportagens & $45(15,2)$ & 31,1 & 1 & \\
\hline Filmes/seriados/novelas/esporte/lazer & $251(84,8)$ & 43,4 & $1,39(0,88-2,21)$ & \\
\hline Conversar sobre sexualidade com amigo/fami- & & & & 0,792 \\
\hline \multicolumn{5}{|l|}{ liar } \\
\hline Sim & $207(69,9)$ & 41,1 & 1 & \\
\hline Não & $89(30,1)$ & 42,7 & $1,04(0,78-1,39)$ & \\
\hline Participou de curso/palestra sobre HIV/Aids & & & & 0,958 \\
\hline Sim & $192(64,9)$ & 41,7 & 1 & \\
\hline Não & $104(35,1)$ & 41,3 & $0,99(0,75-1,31)$ & \\
\hline
\end{tabular}

RP - Razão de prevalência.

* Teste qui-quadrado para heterogeneidade.

Valores em negrito são estatisticamente significativos $(p<0,05)$. 
Gráfico 1 - Frequência de conhecimento, em relação às afirmativas apresentadas aos acadêmicos de um curso de Fisioterapia, em uma instituição privada do sul do Brasil. Caxias do Sul, 2016

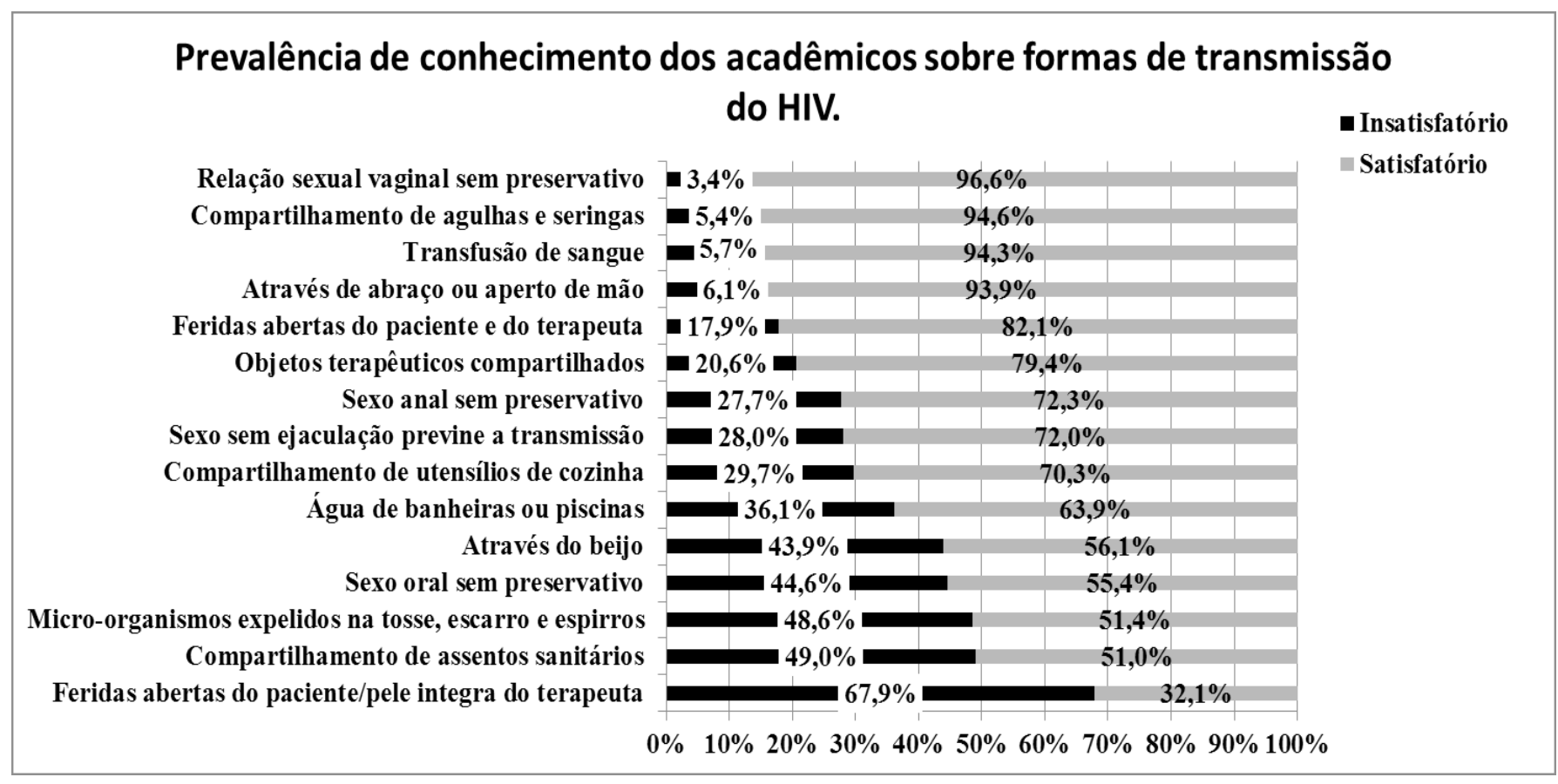

Tabela 3 - Análise ajustada quanto ao conhecimento insatisfatório referente às formas de transmissão do HIV, entre acadêmicos do curso de Fisioterapia, em uma instituição privada do sul do Brasil. Caxias do Sul, 2016

\begin{tabular}{lcc}
\hline Variáveis de exposição & $\begin{array}{c}\text { RP ajustada } \\
\text { (IC95\%) }\end{array}$ & p-valor* \\
\hline${ }^{1}$ Idade (anos) & & $<0,001$ \\
$\geq 22$ & 1 & \\
$\leq 21$ & $1,97(1,39-2,80)$ &
\end{tabular}

${ }^{1}$ Estado civil

Casado (a)/união estável/outros

Solteiro (a)

${ }^{1}$ Moradores na casa do acadêmico

$\leq 3$

$\geq 4$

${ }^{2}$ Disciplinas completas no curso de Fisioterapia

$\geq 50 \%$

$<50 \%$

${ }^{2}$ Objetivo principal de acesso à Internet

Estudos/ buscar material didático

Redes sociais/Lazer

${ }^{2}$ Livros não didáticos lidos no último ano

$$
\geq 3
$$

$\leq 2$

${ }^{2}$ Qual programação costuma assistir na TV

Documentários/reportagens

Filmes/seriados/novelas/esporte/lazer
0,080

1

$1,67(0,94-2,95)$

0,360

1

$1,13(0,87-1,46)$

0,431

1

$1,15(0,81-1,62)$

0,704

1

$1,05(0,80-1,40)$

0,011

1

$1,40(1,08-1,81)$

0,413

1

$1,19(0,78-1,81)$

RP - Razão de Prevalência. Modelo final ajustado pelo método de regressão de Poisson, por todas as variáveis que apresentaram $\mathrm{p}$-valor $\leq 0,20$ na análise bruta.

${ }^{1}$ Variáveis inseridas no nível 1; Ajustadas entre elas;

${ }^{2}$ Variáveis inseridas no nível 2; Ajustadas entre elas e para as variáveis do nível 1. 
costuma assistir na TV. Demais características investigadas não apresentaram valores significativos para o teste qui-quadrado na análise bruta.

$\mathrm{Na}$ análise ajustada, o modelo final apresentou valores estatisticamente significativos $(p<0,05)$ nas variáveis idade e quantidade de livros lidos no último ano $(p<0,05)$. Assim, aqueles acadêmicos com idade $\leq 21$ anos apresentaram uma prevalência $97 \%$ maior de conhecimento insatisfatório quantos às formas de transmissão do vírus HIV quando comparados com os estudantes de idade $\geq 22$ anos. Ainda, os acadêmicos que leram menos no último ano ( $\leq 2$ livros) apresentaram uma prevalência $40 \%$ maior de conhecimento insatisfatório ao serem comparados aos que leram três ou mais livros no mesmo período. Também é possível perceber que acadêmicos solteiros, que estão na primeira metade do curso, com maior quantidade de moradores na casa e que buscam, tanto na Internet como na televisão, opções de lazer, apresentam uma maior prevalência de conhecimento insatisfatório quanto às formas de transmissão do vírus HIV, porém não foram obtidos valores significativos para estas variáveis (Tabela 3).

\section{DISCUSSÃO}

O presente estudo encontrou uma prevalência geral de acadêmicos com conhecimento insatisfatório sobre as formas de transmissão do HIV de $41,6 \%$, todos eles integrantes de um curso de Fisioterapia em uma instituição privada de Ensino Superior do sul do país. A constituição da população investigada, formada por estudantes da área da saúde e a alta prevalência geral de conhecimento insatisfatório revelam um panorama negativo sobre o tema aqui abordado. Neste mesmo sentido, investigações com estudantes da área da saúde ou profissionais apresentam resultados semelhantes, com altas prevalências de conhecimento insatisfatório quanto às formas de transmissão do HIV (HAROUN, 2016).

Em relação ao conhecimento sobre as formas de transmissão do vírus, a falta de conhecimento em aspectos pontuais, os quais possam estar associados à rotina profissional do fisioterapeuta, foram os itens que chamaram a atenção nos resultados da investigação. Acreditar que o compartilhamento de banheiras e piscinas (36,1\% dos acadêmicos), que microrganismos expelidos na tosse, escarros e espirros (48,6\%), que o compartilhamento de assentos sanitários (49\%) e que as feridas abertas dos pacientes em contato com a pele íntegra do terapeuta $(67,9 \%)$ são possíveis formas de transmissão do HIV são percepções equivocadas, as quais podem induzir o futuro fisioterapeu- ta a agir de modo equivocado diante de algumas das situações anteriormente relatadas. Em contrapartida, um estudo realizado com acadêmicos do curso de Medicina, na Malásia, encontrou um bom domínio para questões semelhantes às aqui pesquisadas, no qual $95,1 \%$ dos estudantes apresentaram conhecimento de que o HIV não poderia ser transmitido por meio de espirros e tosse e $89 \%$ sabiam que não era possível ocorrer a transmissão pelo do compartilhamento de banheiras e piscinas (VERMA et al., 2014).

Quanto à transmissão do vírus HIV por meio de assentos sanitários, muitos acadêmicos acreditam ser uma via de transmissão, apresentando então uma alta prevalência de conhecimento insatisfatório. Esta questão também foi investigada por um estudo realizado em março de 2014, nos Emirados Árabes, com uma amostra total de 2.294 acadêmicos de quatro universidades, apresentando uma alta taxa de conhecimento inadequado (29\%). Neste mesmo estudo, houve uma predominância de conhecimento insatisfatório geral na população do sexo masculino, diferentemente desta pesquisa, na qual o sexo feminino apresentou prevalência em conhecimento insatisfatório, ainda que sem significância estatística (HAROUN, 2016).

A alta prevalência de conhecimento insatisfatório em relação à transmissão do vírus HIV por feridas abertas do paciente com a pele íntegra do terapeuta corrobora com os achados de um estudo com delineamento transversal realizado com 265 acadêmicos do curso de Odontologia na Jordânia, em que aproximadamente um quarto da amostra acreditava que o contato da ferida com a pele intacta é uma possível via de transmissão (RYALAT et al., 2011). Este achado é preocupante, uma vez que o fisioterapeuta tem sua atuação realizada por intermédio do toque com o paciente, do contato físico e da aproximação corporal. Relata-se que a falta deste conhecimento poderia gerar atitudes equivocadas e excessivas. Reforça esta afirmação um estudo realizado com 320 dentistas da Índia, o qual revelou que alguns profissionais apresentam determinadas práticas excessivas, por exemplo, o uso de duas luvas, como medida de proteção contra a transmissão do vírus ao atender um paciente HIV positivo (AGARWAL et al., 2015).

Por outro lado, alguns resultados da investigação expõem bom conhecimento quanto à transmissão do vírus HIV por meio de compartilhamento de aguIhas e seringas, relações sexuais (vaginal/anal) sem proteção e transfusão de sangue. Neste mesmo sentido, estudos internacionais revelaram achados semeIhantes, em que as formas de transmissão pelos meios anteriormente citados também foram aquelas sobre 
as quais os indivíduos demonstraram maior domínio de compreensão. Esta associação entre o alto entendimento sobre as formas mais comuns de transmissão da doença poderia ter explicação na mídia, pois os meios principais de contaminação, abordados com maior frequência por veículos de comunicação, poderiam auxiliar na construção do conhecimento dos indivíduos. Já as formas de transmissão menos prevalentes dificilmente são apresentadas e discutidas nos programas de televisão, na Internet ou em campanhas preventivas (VERMA et al., 2014; CHAVES, 2014).

Ainda em relação à utilização dos meios de comunicação para construção de conhecimento, os resultados aqui apresentados não apontaram associação significativa entre o tempo diário assistindo televisão ou navegando na Internet e maiores domínios das formas de transmissão do HIV. Estes resultados foram opostos à hipótese inicial da investigação, a qual acreditava encontrar maior conhecimento nos alunos com mais tempo diário de contato com estes meios de mídia, visto que jornais, televisão, rádio e Internet são apontados, em alguns estudos, como principais fontes de informações (MEMISH et al., 2015; CHAVES, 2014; GONÇALVES et al., 2013). Percebe-se, porém, que os acadêmicos que costumam utilizar estes meios de comunicação principalmente para o lazer, apresentaram, mesmo que não significativa estatisticamente, uma maior prevalência de conhecimento insatisfatório comparado àqueles que os usam para fins didáticos (estudos/buscar apoio didático), ou até mesmo costumam assistir documentários e reportagens. Ressalta-se, ainda, que o número de acadêmicos que buscam o lazer foi consideravelmente maior, valor este que pode estar associado à não relação de nível de conhecimento com a utilização de meios de comunicação.

Levando em consideração o estado civil, os solteiros apresentam um maior nível de conhecimento insatisfatório, podendo isto estar relacionado com outra variável que também foi investigada - a idade - a qual apresentou maior nível de conhecimentos insatisfatórios nos acadêmicos com idade menor ou igual a 21 anos. Essa relação pode ocorrer a partir do pressuposto de que acadêmicos mais jovens geralmente são solteiros. Um estudo brasileiro descritivo foi realizado em um hospital no município de Natal, com o objetivo de caracterizar, quanto aos aspectos sociodemográficos e de saúde, pacientes portadores de HIV que são atendidos no ambulatório do hospital. Neste estudo foi identificado que solteiros compunham a maior parte da amostra, ou seja, 144 pacientes de um total de 313 , representando $46 \%$ da população (SILVA et al., 2010). Os jovens de 15 a 24 anos representam
$45 \%$ das novas infecções no mundo, sendo classificados como um grupo vulnerável à doença, principalmente por revelarem atitudes de risco, terem uma vida sexual mais ativa e consequentemente apresentarem um maior número de parceiros sexuais. Isso posto, torna-se preocupante o fato de que os jovens estejam desinformados quanto aos fatores de transmissão, podendo esse desconhecimento aumentar o risco de propagação do vírus (MONTES et al., 2014).

Apesar da alta prevalência geral de conhecimento insatisfatório encontrada no estudo, destaca-se que aqueles alunos que concluíram $50 \%$ ou mais das disciplinas ofertadas durante o curso de Fisioterapia foram os que obtiveram menores prevalências em relação ao desfecho. Esta associação pode apontar que o decorrer da realização do curso influencia na construção do conhecimento quanto às formas de transmissão do vírus HIV. Achados semelhantes foram encontrados em outros estudos (MAGALHÃES; OLIVEIRA; PRADO, 2015; SAHILE; MEKURIA; YARED, 2015), em que acadêmicos mais avançados na trajetória acadêmica demonstram um maior nível de conhecimento, fato que pode estar relacionado com a preparação didática, as experiências práticas e os estágios. A relevância de ações realizadas em Instituições de Ensino Superior, voltadas para a obtenção da informações sobre as formas de transmissão do HIV são extremamente importantes. Um estudo brasileiro, realizado com acadêmicos de um curso de Farmácia de uma universidade particular de Campo Grande - MS, revelou que apenas $11,36 \%$ dos alunos relataram receber um treinamento profissional para prestar atendimento a uma pessoa com Aids, visto que cabe à instituição, como formadora de profissionais da saúde, preparar os alunos para receber todo o tipo de público (VASCONCELOS; COÊLHO, 2013).

Quanto ao hábito de leitura, percebe-se que este costume apresentou forte relação com o domínio de conhecimento sobre o tema aqui abordado. Sabe-se que a leitura possibilita ampliar e adquirir novos conhecimentos, melhorando o desempenho cognitivo, capacidade cultural e de civilização. $O$ hábito da leitura pode estimular os valores éticos, estéticos e humanísticos. Uma pesquisa que buscou identificar mudanças na massa branca encefálica por meio do hábito da leitura verificou que ocorre um desenvolvimento desta massa a partir da leitura contínua. Relata, ainda, que conteúdos impressos contêm mais conhecimento declarativo e maior vocabulário do que palestras e televisão, e que o hábito saudável de leitura produz vários efeitos positivos entre os acadêmi- 
cos, aumento do conhecimento geral, melhoria das habilidades de linguagem oral, escrita e ótimo sucesso acadêmico (TAKEUCHI et al., 2016).

Devido à falta de um questionário validado, em português, o instrumento aqui utilizado para coleta de dados foi desenvolvido por meio da revisão de literatura, pelos pesquisadores envolvidos no estudo, o qual pudesse atingir os objetivos propostos na investigação. Um estudo- piloto, com população praticamente idêntica àquela investigada, auxiliou na elaboração final do questionário, buscando-se, assim, evitar erros sistemáticos que invalidassem os achados. Destaca-se que as variáveis utilizadas para medir o desfecho foram construídas mediante observações em estudos com populações que apresentassem características semelhantes a essa, no entanto possíveis variáveis que auxiliassem a medir o conhecimento quanto às formas de transmissão do vírus HIV, principalmente entre as atribuições profissionais dos fisioterapeutas, podem não ter sido incluídas no estudo, constituindo um dos pontos vulneráveis da investigação.

Da mesma forma, as limitações dos estudos epidemiológicos observacionais transversais são a possibilidade de viés de seleção e a causalidade reversa. 0 presente estudo, no entanto, buscou investigar todos os acadêmicos matriculados no curso de Fisioterapia da instituição, evitando uma seleção amostral equivocada. Em relação à causalidade reversa, buscou-se utilizar variáveis que diminuíssem as dificuldades para medir associação entre as características de exposição e o conhecimento sobre as formas de transmissão do vírus HIV, contudo o delineamento transversal foi utilizado em razão de critérios logísticos e orçamentários.

\section{CONCLUSÃO}

Identificou-se que existe alta prevalência de conhecimento insatisfatório sobre as formas de transmissão do vírus HIV entre os acadêmicos de um curso de Fisioterapia em uma instituição privada de Ensino Superior do sul do país. Também destaca-se que níveis mais elevados de conhecimento insatisfatório foram encontrados em acadêmicos mais jovens ou menores de 21 anos, solteiros e que não costumam ter o hábito da leitura.

Positivamente, esta investigação tem relevância na construção ou aprimoramento do conhecimento das formas de transmissão do HIV para os profissionais da área da saúde, especialmente os acadêmicos ou fisioterapeutas. Nessa perspectiva, os resultados apresentados poderão auxiliar na atuação profissional destes indivíduos, melhorando o conhecimento e cui- dados com a transmissão do HIV, diminuindo o risco de contaminação ocupacional e evitando, assim, atitudes negativas, medidas excessivas e comportamentos discriminativos dos trabalhadores da saúde para com os pacientes. Além disso, coloca em destaque um tema de grande importância para as instituições de ensino e mostra a necessidade da adoção de programas de prevenção nas instituições com questões que abordem as medidas preventivas e formas de transmissão para a prática de cada profissional.

Por fim, diante deste cenário, intervenções educativas surgem como proposta para melhorar estes déficits de conhecimento técnico nos profissionais da área da saúde, em especial os fisioterapeutas, para que assim estes possam atuar com maior segurança e consequentemente diminuir novos casos de infecções pelo vírus HIV. Nesse sentido, sugere-se que novas intervenções sejam realizadas na busca da consolidação dos achados aqui discutidos.

\section{REFERÊNCIAS}

AFFELDT, Â. B.; SILVEIRA, M. F. D.; BARCELOS, R. S. Perfil de pessoas idosas vivendo com HIV/Aids em Pelotas, sul do Brasil, 1998 a 2013. Epidemiol. Serv. Saúde, v. 24, n. 1, p. 79- 86, 2015.

AGARWAL, J. et al. Analysis of Information, Impact and Control of HIV amongst Dental Professionals of Central India. J. Clin. Diagn. Res., JCDR. v. 9, n. 7, p. ZC80- ZC84, 2015.

ARIAS, J. A. C.; LUJÁN-TANGARIFE, J. A. Construcción y evaluación de una escala de conocimientos, actitudes y prácticas sobre VIH/Sida en adolescentes universitarios de Medellín. Salud Uninorte, v. 31, n. 2, p. 201- 213, 2015.

CHAVES, A. C. P. et al. Conhecimentos e atitudes de adolescentes de uma escola pública sobre a transmissão sexual do HIV. Rev. Bras. Enferm., v. 67, n. 1, p. 48- 53, 2014.

FAROTIMI, A. A.; NWOZICHI, C. U.; OJEDIRAN, T. D. Knowledge, attitude, and practice of HIV/Aids-related stigma and discrimination reduction among nursing students in southwest Nigeria. Iranian Journal of Nursing and Midwifery Research, v. 20, n. 6, p. 705-711, 2015.

GONÇALVES, $H$. et al. Conhecimento sobre a transmissão de HIV/Aids entre adolescentes com 11 anos de idade do Sul do Brasil. Rev. Bras. Epidemiol., v. 16, n. 2, p. 420- 431, 2013.

HAMERSHOCK, R. A. et al. Dental Students' HIV/Aids-Related Knowledge, Attitudes, and Intentions: Impact of the US Health Resources and Services Administration's Community-Based Dental Partnership Program. J. Dent. Educ., v. 78, n. 8, p. 1.106-1.117, 2014.

HAROUN, D. et al. Assessing Knowledge of, and Attitudes to, HIV/Aids among University Students in the United Arab Emirates. PloS ONE, v. 11, n. 2, p. e0149920, 2016. 
KUMAR, V.; PATIL, K.; MUNOLI, K. Knowledge and attitude toward human immunodeficiency virus/acquired immuno deficiency syndrome among dental and medical undergraduate students. Journal of pharmacy \& bioallied sciences, v. 7, n. Suppl 2, p. S666, 2015.

MAGALHÃES, V. C. S. D.; OLIVEIRA, D. L. D.; PRADO, F. O. Knowledge, risk perception and attitudes of Dentistry students with regard to HIV/Aids. Rev. Gauch. Odontol., v. 63, n. 3, p. 291-300, 2015.

MARZÁN-RODRÍGUEZ, M.; VARAS-DÍAZ, N. Qualitative Contributions to a Randomized Controlled Trial Addressing HIV/ Aids-Stigma in Medical Students. The Qualitative Report, v. 20, n. 12, p. 2.012-2.024, 2015.

MEMISH, Z. A. et al. Knowledge and attitudes about HIV/ Aids in illegal residents in the Kingdom of Saudi Arabia. Journal of global infectious diseases, v. 7, n. 3, p. 103-107, 2015.

MONTES, C. E. D. et al. Conocimientos sobre VIH/Sida en adolescentes de una universidad en Cartagena-Colombia, 2011. Revista Hacia la Promoción de la Salud, v. 19, n. 2, p. 38- 52, 2014.

MOURA, M. D. G. et al. Development of questionnaire on dentists' knowledge of HIV/Aids. Arq. Odontol., v. 50, n. 1, p. 06- 12, 2014.

PUNDE, P. A.; PUNDE, S. Comprehensive Survey to Study Awareness, Knowledge and Attitude Towards HIV/Aids and Hepatitis B Amongst Dental Professionals Working in Rural India. J. Oral. Maxillofac. Surg., v. 13, n. 4, p. 483- 487, 2014.

RYALAT, S. T. et al. The knowledge and attitude about HIV/ Aids among Jordanian dental students:(Clinical versus pre clinical students) at the University of Jordan. BCM res notes, v. 4, n. 1, p. 191, 2011.

SAHILE, Z.; MEKURIA, M.; YARED A. Comprehensive HIV/ Aids Knowledge and Sexual Behavior among University Students in Ambo, Central Ethiopia: Implication to Improve Intervention. Journal of sexually transmitted diseases, v. 2015, p. 1- 6, 2015.

SILVA A. P. et al. Conhecimento e percepção de vulnerabilidades para o HIV/Aids entre os acadêmicos de uma universidade privada. Rev. Enferm., Uerj, v. 21, n. 1, p. 618-623, 2013.

SILVA, R. A. R. D. et al. Características epidemiológicas e clínicas de portadores de HIV/Aids atendidos em um hospital de referência - Natal/RN/Brasil. Fiep Bulletin on-line, v. 80, n. 2, 2010.

TAKEUCHI, H. et al. Impact of reading habit on white matter structure: Cross-sectional and longitudinal analyses. Neurolmage, v. 133, p. 378-389, 2016.

VASCONCELOS, D. C. D.; COÊLHO, A. E. L. Conhecimentos, atitudes e percepção de risco dos acadêmicos de farmácia frente a Aids. Revista Psicologia e Saúde, v. 5, n. 2, p. 109117, 2013.

VASCONCELOS, D. C. D.; FELIX, Y. T. M. Conhecimentos, atitudes e percepção de risco: a visão dos alunos do curso de psicologia sobre a Aids. Fiep Bulletin on-line. v. 85, n. 1, 2015.
VERMA, R. K. et al. An Assessment of the Level of Awareness, Attitudes, and Opinions of the Medical Students Concerning HIV and AIDS in Malaysia. J. Clin. Diagn. Res., v. 8, n. 4, p. HC10-HC13, 2014.

WORLD HEALTH ORGANIZATION. (WHO). Unaids: Global Aids response progress reporting 2015. Disponível em: <http://www.unaids.org/sites/default/files/media_asset/ JC2702_GARPR2015guidelines_en.pdf>. Acesso em 10 out. 2016. 